\title{
LA FORMACIÓN SACERDOTAL: ¿ESTÁ SUPERADO EL VATICANO II?
}

\author{
Mons. Héctor Rubén Aguer
}

Lectio brevis del 7 de marzo de 2018 con motivo de la inauguración del año académico en el Seminario Mayor San José de La Plata, dictada por S.E.R. Mons. Héctor Aguer, entonces arzobispo de La Plata y hoy arzobispo emérito de la misma Arquidiócesis.

Por sugerencia del Padre Rector, dedico esta lección inaugural a presentar una visión de conjunto de la formación sacerdotal, en la que se proyectan no sólo mis estudios sino también mi experiencia eclesial, sobre todo los once años vividos como organizador y director del Seminario Diocesano de San Miguel y luego mi continua cercanía, como arzobispo, de este Seminario Mayor San José. Pero es mi propósito centrar la atención en los textos del Concilio Vaticano II, leídos, como varias veces lo ha indicado Benedicto XVI, según el principio hermenéutico de continuidad con la Gran Tradición de la Iglesia. En mi opinión, la gran Asamblea Ecuménica del siglo XX comprende tres fenómenos, que muchas veces suelen ser confundidos, para daño de su correcta interpretación. El primero es el acontecimiento histórico, el primero en cuanto tal: su convocatoria por San Juan XXIII, la consiguiente preparación y los debates desarrollados en el aula -la basílica de San Pedro- sin descartar los trabajos de las comisiones que elaboraron las propuestas y los contrastes entre diversas posiciones teológicas y pastorales. Sobre esta primera faceta de lo que indistintamente se llama "el Concilio", deberán pronunciarse los historiadores dentro de cien años, para ofrecer a los contemporáneos de entonces un juicio global, habida cuenta, por cierto, de la deliberación de los Padres conciliares concretada en los documentos aprobados de ese Concilio, que quiso ser pastoral antes que dogmático, de su recepción por 


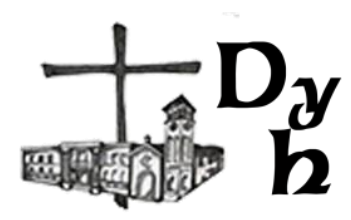

la Iglesia y de la aplicación de las reformas decididas por la Santa Sede. Ellos, los historiadores de entonces, aventajados con la distancia que otorga el tiempo, y liberados de prejuicios, con métodos rigurosos de investigación, podrán determinar en qué medida se trató de un hecho de gloria o quizá de calamidad para la Iglesia. $O$ de ambas cosas, bajo la permisión de la inescrutable providencia de Dios. La segunda dimensión está dada por los documentos conciliares, eso es el Concilio, así como actualmente identificamos a Trento y al Vaticano I por lo que ha quedado de ellos en el celebérrimo Enchiridion Symbolorum, de Denzinger, sin olvidar que, como ya lo he recordado, el Segundo Vaticano se autodefinió pastoral, y no dogmático, aun cuando no faltara en sus Constituciones y en los otros géneros magisteriales adoptados, materia dogmática. En la teología del Concilio de los Papas Juan y Pablo se refleja, como es natural, la teología del siglo XX y los movimientos de renovación bíblica, litúrgica, teológica y espiritual que propusieron con numerosas iniciativas una necesaria "vuelta a las fuentes". Se suma a esas dos identidades que he atribuido al Concilio, a saber: el hecho histórico y los documentos aprobados, lo que ha dado en llamarse "el espíritu del Concilio". Esta denominación ha caído casi en desuso, pero durante medio siglo fue la bandera de todas las arbitrariedades doctrinales $y$ prácticas que abrieron en el cuerpo eclesial llagas dolorosas de división, de cismas expresos o disimulados, de alteración de la continuidad de vida reflejada en el desarrollo homogéneo de la verdad católica, evolución que ha procedido siempre in eodem scilicet dogmate, eodem sensu, eademque sententia, como reza la regla de oro de toda auténtica renovación. Al igual que en tantas otras encrucijadas de su historia que ya la ha introducido en su tercer milenio, la Iglesia de Cristo se encamina hacia la Parusía del Señor confortada por el Espíritu Santo, iluminada por el magisterio petrino y por el testimonio continuo de los santos, mártires, confesores y vírgenes.

Apoyado en estas premisas, me permito presentarles sucintamente -eso espero, que esta lectio no sea en lo posible demasiado extensa- la enseñanza conciliar sobre el presbiterado y la formación para el mismo. El itinerario formativo ha sido trazado por la Santa Sede en sucesivas intervenciones, desde las iniciales reformas y la primera Ratio Fundamentalis

Institutionis

Sacerdotalis promulgada por el Beato Pablo VI a comienzos de 1970, hasta la reciente y vigente, de fecha 8 de diciembre de 2016, que lleva aquella misma expresión como subtítulo, y se llama El don de la vocación presbiteral. Entre ambas se sitúa la que treinta años antes, el 19 de marzo de 1985, concretaba una decisión de San Juan Pablo II, quien aportó pocos años después, el 25 de marzo de 1992, amplios fundamentos teológicos, espirituales y pastorales en su Exhortación 
Apostólica Postsinodal Pastores dabo vobis. Conviene volver a leerla, o leerla si no se lo ha hecho. Los acentos de cada una de aquellas tres orientaciones autoritativas de 1970, 1985 y 2016 se remiten a la ratio del presbiterado expuesta en los documentos del Vaticano II. Ratio significa razón, mente, naturaleza, condición, cualidad, y también camino, método, regla. El itinerario de formación de un presbítero tiene su base en una teología del presbiterado. La que expuso el Concilio, reconociendo y aun descontando las peculiaridades epocales, no está superada. De ninguna manera.

El parágrafo 28 de la Constitución Dogmática Lumen gentium, sobre la Iglesia, promulgada al término de la tercera etapa conciliar, el 21 de noviembre de 1964, está dedicada al presbiterado, $\mathrm{y}$ contiene in nuce lo que se ha de desarrollar en los otros documentos de los cuales me ocuparé en esta conferencia. Ante todo, me parece oportuno señalar la diferencia de enfoques respecto de la Encíclica de Pío XII Menti nostrae publicada en 1950, en la que no se emplea el nombre presbiteros para designar a los sacerdotes. El Vaticano II vuelve su atención a la más antigua tradición, anclada en el Nuevo Testamento. En efecto, además del significado genérico de anciano, la palabra presbiteros designa al jefe de la comunidad, instituido por los apóstoles; aparece en el libro de los Hechos 14, 13 y con cuatro menciones en el capítulo 15, en la descripción de la reunión o concilio de Jerusalén, donde los presbíteros acompañan a los apóstoles en las decisiones tomadas. Para no detenerme en todas las citas neotestamentarias posibles, menciono solamente la Primera Carta de Pedro: al dirigirse a los presbíteros, el apóstol se designa a sí mismo como sympresbýteros, copresbítero, presbítero como ellos (1 Pe, 5, 1). La distinción entre epískopos y presbíteros se establece rápidamente en el lenguaje. San Ignacio, obispo de Antioquía y discípulo del apóstol Juan, en sus cartas, compuestas mientras era conducido prisionero a Roma donde sufrió el martirio en los primeros años del siglo II, presenta la estructura definitiva del ministerio eclesial. La Iglesia es, concretamente, la Iglesia local, en la que el obispo representa a Dios Padre, el presbiterio al colegio de los apóstoles, y los diáconos a Jesucristo. La Iglesia Romana es la que preside el agápe de toda la cristiandad. Una temprana indicación sobre su primacía.

No quiero dejar caer la referencia a la encíclica de Pío XII, que aunque refleja la teología de la primera mitad del siglo $\mathrm{XX}$, conserva en varios aspectos una notable actualidad. Algunas advertencias allí apuntadas permiten comprender con qué imprudencia muchos clérigos difundieron errores doctrinales $y$ prácticas contrarias a la moral cristiana durante los años posconciliares; y hay otros que lo 
siguen haciendo hoy día. Destaco una observación bien aguda:

se está desarrollando entre los sacerdotes, cada día más extensa y gravemente, el ansia de novedades, en especial entre aquellos que están menos dotados de erudición y doctrina y llevan una vida menos ejemplar.

Diríamos que los "macaneadores" suelen ser los que ignoran todo y hacen lo que les viene en gana. Aunque no faltan, es verdad, profesores renombrados que hacen mucho daño con sus publicaciones, incluso heréticas, y permanecen impunes. Buscaba el Papa Pacelli el punto justo, sobre todo respecto de los métodos apostólicos, entre la desbordada ansia de novedades de unos y el aferramiento al pasado de otros. El punto preciso de la prudencia, virtud clave de la vida pastoral, que como escribía el Pontífice, es siempre sabia y avisada. Un fenómeno análogo se registró más tarde, cuando se pretendió imponer un cierto "espíritu del Concilio". Los pensadores católicos que prepararon la renovación conciliar reaccionaron lúcidamente al advertir el desbarajuste que se precipitaba en la Iglesia, y lo consignaron en obras que señalaban los errores e indicaban el camino correcto. Balthasar en "Córdula o el caso auténtico", Bouyer en "La descomposición del catolicismo", Congar en "En medio de las tormentas", de Lubac en "La Iglesia en la crisis actual". Todas ellas publicaciones de 1968 y 1969. Al año de concluir el Concilio, ya Maritain dio la voz de alarma en un libro magnífico: "El campesino del Garona. Un viejo laico se interroga a propósito del tiempo presente".

En la etapa final del Concilio, el 28 de octubre de 1965 se realizó la votación final y se promulgó el Decreto Optatam totius Ecclesiae renovationem, sobre la formación sacerdotal. Un principio fundamental es enunciado en el número 8: la dimensión espiritual de la formación ha de estar estrechamente unida a la doctrinal y a la pastoral. Este enunciado puede parecer una perogrullada, sin embargo, no resulta fácil instrumentarlo lúcida y eficazmente en un itinerario que no se reduce al currículo académico, sino que es vital, es decir se trata del intento de plasmar una personalidad sacerdotal. Tal objetivo compromete a los formadores, que han de proponerlo en la objetividad de la organización del Seminario, y revisar periódicamente su cumplimiento, pero también a la decidida y gozosa voluntad de los seminaristas. ¿Qué han de aprender éstos? A vivir en el trato familiar con el Dios Trino y a forjar una especial amistad con Jesús, a quien se van a configurar un día en el sacerdocio. Se trata -continúa el texto- de vivir secundum formam Evangelii. Pensemos en el significado de la noción de forma en la teoría hilemórfica; por tanto, la referencia indica el alma, de cimentarse en la fe, la esperanza y la caridad para alcanzar el espíritu de oración, el vigor de las demás virtudes y el celo 
por ganar a todos los hombres para Cristo. Son estas expresiones casi literales del texto. La formación espiritual conlleva una ambición de totalidad; nada debe quedar a medias. El ejercicio total del amor se extiende de Cristo a la Iglesia, que es inseparable de Él. A este propósito se cita un pasaje del Comentario de San Agustín al Evangelio de Juan, en la medida que uno ama a la Iglesia de Cristo, posee el Espíritu Santo (Tractatus 32, 8).

Se registra también una cuádruple referencia a la madurez de la personalidad. El crecimiento en una madurez más plena, asociada al dominio del cuerpo y del espíritu, y como consecuencia a la percepción y goce de la Evangelii beatitudinem ( $\mathrm{n}$. 10), la felicidad, la dicha que proporciona el Evangelio. La adquisición del dominio de sí mismo y la debita maturitas humana, la solidam personae maturitatem, que ha de ser el fruto del ritmo de la vida propio del seminario, equivalen a la estabilidad del ánimo bajo el régimen de la caridad, a templar el carácter, lo cual permite el uso recto de la libertad y una experiencia pastoral sincera y sin reservas (n. 11). La cuarta mención de la madurez se refiere a la seriedad de la opción vocacional, optione mature deliberata (n. 12). El concepto de madurez no debe restringirse a la sola dimensión psicológica. Por cierto, ésta debe quedar asegurada, a lo cual puede ayudar el recurso profesional correspondiente cuando se advierte necesario, pero aquí se trata sobre todo de un nivel espiritual de realización de la persona, de orden natural y sobrenatural. La inteligencia, la afectividad, la voluntad y la gracia. ¿Quién alcanza plenamente esa madurez? Pienso que los santos; todos nosotros -yo al menos- nos encaminamos hacia esa meta, vamos penosamente a veces, subiendo la cuesta, avanzamos gradualmente, gradatim, como dice el texto conciliar; la alegría que es propia de la esperanza alivia la fatiga, que no nos es ahorrada. He conocido jóvenes tempranamente maduros, y viejos tilingos. Una observación muy válida: la disciplina, el orden exterior imprescindible en el Seminario, debe convertirse en interna aptitudo, íntima convicción de abrazar el orden, y por razones sobrenaturales.

En relación con el tema de la madurez, el Decreto se refiere brevemente al celibato sacerdotal, a la educación para el mismo. Por este don, que es a la vez tarea continua, el presbítero entrega al Señor un corazón indiviso, para amar a todos como él los ama; es preciso pedirlo humildemente, y siempre. El Concilio exhorta a los responsables a no callar las dificultades que los candidatos tendrán que afrontar, pero sin mirar casi exclusivamente el peligro (n. 9). La renuncia al matrimonio se hace en orden a un amor más grande, y mirando al reino de los cielos. En el n. 10 hay una advertencia acerca de los peligros que acechan a la castidad del sacerdote, máxime en la sociedad actual. ¡Esto se decía en los años 60 del siglo pasado! ¿Qué tendríamos que advertir hoy, en una sociedad que exhibe $\sin$ recato 


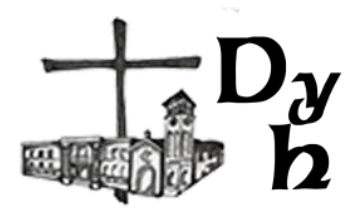

alguno, en protagonistas populares, su gusto ostentoso de la fornicación? Recuerdo qué pacatos eran, en tiempos de mi infancia y adolescencia, los amoríos de la gente de la farándula; hoy día cualquier hijo o hija de vecino puede exhibir su intimidad, solo o en compañía, usando nomás el telefonito. Este influjo en la imaginación masiva, y las actitudes desprejuiciadas en la conducta y el trato interpersonal, no puede ser favorable. El Concilio infundía ánimo mencionando los oportunos auxilios divinos y humanos; lejos de menoscabar la vida, el celibato la transporta a una feliz y fructuosa plenitud, al costo de un sereno cultivo de la castidad y de los cuidados que la protegen.

La cuestión del celibato es retomada en otro documento conciliar, el Decreto Presbyterorum ordinis, votado y promulgado en la última sesión pública, el 7 de diciembre de 1965. Quedó allí formulada una expresión muy lograda del valor y excelencia del celibato, mediante el empleo de cinco comparativos: facilius, liberius, expeditius, aptiores, latius; cuatro adverbios y un adjetivo. Se abraza el celibato para unirse más fácilmente a Cristo, sin competencia; para dedicarse con mayor prontitud al servicio de Dios y de los hombres, porque uno se entrega con mayor libertad al Señor; para ser más aptos a recibir una más dilatada paternidad. Si esta argumentación no era necesaria en el contexto de una cultura fuertemente marcada por el cristianismo, más tarde, y ahora, se ha tornado necesaria para robustecer las convicciones, superar las dudas y para responder a las críticas.

Dos años después, el Beato Pablo VI dedicó al tema la Encíclica Sacerdotalis caelibatus, publicada el 24 de junio de 1967; era un tiempo de enorme confusión, con la que se difundían ampliamente numerosos errores $y$ se registraron dolorosas deserciones de la vida sacerdotal, incluso entre superiores y profesores de los seminarios. Cito un pasaje bien ponderado de ese texto. Recordaba el Pontífice que la formación para el celibato debe mirar a una serena, convencida y libre elección del compromiso que se va a asumir, y añadía: el ardor y la generosidad son cualidades admirables de la juventud e, iluminadas y promovidas con constancia, le merecen, con la bendición del Señor, la admiración y la confianza de la Iglesia y de todos los hombres. Retoma, el texto del Papa Montini, lo que ya he señalado como cautela en el Decreto Optatam:

A los jóvenes no se les ha de esconder ninguna de las verdaderas dificultades personales y sociales que tendrán que afrontar con su elección, a fin de que su entusiasmo no sea superficial y fatuo; pero a la par de las dificultades, será justo poner de relieve con no menor verdad y claridad lo sublime de la elección, la cual, si por una parte provoca en la persona humana un cierto vacío físico y psíquico, por otra aporta una plenitud 


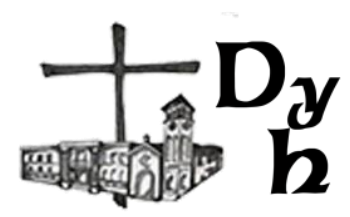

interior capaz de sublimarla desde lo más hondo (n. 69).

Es esta una bella página de realismo sobrenatural, de realismo católico.

Reanudo el comentario de Optatam totius. A continuación, el Decreto sobre la formación sacerdotal ofrece orientaciones sobre los estudios. Menciona en primer lugar las humanidades; este término se refiere a las letras humanas, a la cultura clásica y moderna, lo que antiguamente se impartía en el Seminario Menor, que era una especie de bachillerato especializado. ¿Cómo se suple, siquiera mínimamente, la carencia de letras, y arte, y música, y ciencias, cuando la educación anterior no la ha proporcionado? El Concilio habla de formación humanística y científica, y de lenguas, sobre todo el estudio de la lengua del propio rito. ¿Cuál será la lengua de nuestro propio rito, con tanta frecuencia desritualizado? ¡Cuánta agua ha corrido bajo los puentes en medio siglo! El texto, en el n. 13, sugiere un Curso Introductorio. Yo diría, la adquisición, en lo posible, del nivel cultural que sería necesario para emprender los estudios superiores. En un país normal, por supuesto. Se me ocurre que, más allá de lo que se pueda implementar curricularmente, no sería difícil suscitar el interés de los jóvenes mediante diversas iniciativas, en especial para asomarse a ese fabuloso acopio de sabiduría y belleza reunido, siglo tras siglo, por la humanidad y por la Iglesia. El interés, y más aún, el amor, la pasión. Advertencia mía: No es lo mismo una persona culta que una "culterana", o "cultósica", que ostenta la superficialidad de un diletante. Quizá convendría en este campo facilitar inclinaciones personales o grupales, facilitar su desarrollo.

En cuanto a los estudios filosóficos, la finalidad que se propone es adquirir un conocimiento sólido y coherente del hombre, del mundo y de Dios, apoyados en el patrimonio filosófico de perenne validez (n. 15). En este Seminario Platense la expresión conciliar respecto de tal patrimonio filosófico se traduce tomismo. Lo han cultivado y transmitido hombres insignes como Derisi, Blanco, Ponferrada, y tantos otros como lo siguen haciendo los profesores Ayala y Mayeregger, aquí presentes; no quiero ser injusto olvidando nombres. Uno de mis maestros, el Padre Julio Meinvielle, me ha inculcado que a Santo Tomás hay que estudiarlo en sus textos, no en manuales; siendo un adolescente, y antes de entrar al Seminario, asistía los domingos a la mañana a sus sesiones de lectura de la Summa. Esos empeños juveniles me sirvieron luego como base para atreverme más o menos profesionalmente a aplicar a otros textos del Angélico métodos hermenéuticos más sutiles y complejos. Frecuentar a Santo Tomás ayuda a armar la cabeza, para decirlo popularmente. El texto conciliar no omite mencionar la importancia de la filosofía moderna y contemporánea, que han marcado 
profundamente la cultura vigente, también el modo de pensar de aquellos que jamás han oído hablar de los jefes de fila de la filosofía de los últimos dos o tres siglos. El propósito de estos estudios consiste en

suscitar en los alumnos el amor a la verdad, la cual ha de ser rigurosamente buscada, observada y demostrada, reconociendo al mismo tiempo con honradez los límites del conocimiento humano (n. 15).

En una nota, el texto ofrece como referencia la Encíclica Humani generis, de Pío XII, y la alocución pronunciada por Pablo VI en la Universidad Gregoriana el 12 de mayo de 1964. El problema de la verdad se

plantea contemporáneamente de modo más serio y radical que medio siglo atrás, a causa de una difusión masiva, y del contagio cultural del relativismo y del constructivismo. ¿La verdad? Digámoslo con lenguaje de barrio: $\mathrm{O}$ es considerada inalcanzable, o cada uno tiene la suya, o la construyen los "formadores de opinión".

Se reconoce a la Sagrada Escritura como alma de toda la teología: universae theologiae veluti anima esse, y no falta la referencia a la tradición patrística de los "dos pulmones" de la Iglesia, Oriente y Occidente, con su rica diversidad. El objetivo de la teología dogmática es ilustrar de la forma más completa posible los misterios de la fe, profundizar en ellos y descubrir su conexión por medio de la especulación, Sancto Thoma magistro. En las sucesivas décadas a partir de los 60 se multiplicaron las "teologías de..."; de la creación, de la liberación, del trabajo, del pueblo (latinoamericano o argentino), del medio ambiente, de la masa, etc. Falta dedicarse con mayor profundidad y pertinencia a la teología de Dios. Eso es la teología. Aún actualmente, en algunos centros superiores de estudios teológicos hay profesores que afirman que "Santo Tomás no va más", desacreditan su obra y la de sus comentaristas y los estudiosos que toman al Aquinate por referencia, como si la tradición filosófica y teológica del tomismo no hubiera aportado nada nuevo. Tomismo no es "lo mismo"; basta citar la obra de Cornelio Fabro, en filosofía o de Jean-Hervé Nicolas, y tantos otros en teología. En un juicio negativo como aquel sólo puedo ver ignorancia o prejuicio.

Para manifestar cómo la teología tiene que convertirse en alimento de la vida espiritual, se cita en la nota 32 un pasaje del Itinerarium mentis in Deum de San Buenaventura:

No crea nadie que le basta la lectura sin la unción, la especulación sin la devoción, la investigación sin la admiración, la circunspección sin el regocijo, la pericia sin la piedad, la ciencia sin la caridad, la inteligencia sin la humildad, el estudio sin la gracia divina, el espejo sin la sabiduría inspirada por Dios. 
Me recuerda aquel aforismo de Evagrio Póntico en su "Tratado sobre la oración", si eres teólogo, orarás verdaderamente, y si oras verdaderamente, eres teólogo. Esta apropiación vital de la teología es imprescindible. Sin embargo, no debe olvidarse que la teología, ciencia de Dios, es auténticamente ciencia, y pueda reivindicar, con todo derecho un lugar en el ámbito universitario. A este respecto, es decisiva la argumentación de Benedicto XVI en su célebre "discurso de Ratisbona", pronunciado en aquella universidad estatal alemana el 12 de septiembre de 2006. Allí subsisten hasta hoy dos facultades de teología: una católica y otra protestante. El Papa Ratzinger se reconoce como buenaventuriano; es un doctor de la Iglesia, pero ante todo hombre de Dios.

Después de tratar de la teología dogmática, el Decreto conciliar menciona rápidamente las otras disciplinas: la teología moral, el derecho canónico y la historia eclesiástica. Respecto de la sagrada liturgia anota que hay que considerarla como la fuente primera y necesaria del genuino espíritu cristiano, y remite a la Constitución Sacrosanctum Concilium, que fue el primer documento, votado $y$ promulgado al concluir la segunda etapa conciliar, el 4 de diciembre de 1963. El Papa Pío XII, considerado muchas veces como un peligroso y olvidable conservador preconciliar, fue un pontífice renovador en todos los ámbitos de la vida eclesial, pero advirtió proféticamente adónde llevaría en lo doctrinal y en lo práctico el predominio de lo que llamó "ansia imprudente de novedades". En la Encíclica Mediator Dei et hominum, de 1947, asumió el movimiento de renovación litúrgica, advirtiendo sobre las deficiencias de algunos y los excesos de otros respecto de una genuina instauratio de la liturgia eclesial. La obra del Vaticano II avanza sobre los mismos carriles remitiéndose a la riqueza de una tradición que había quedado como detenida, anquilosada, de hecho fue él, el Papa Pacelli, quien, entre otras reformas nos devolvió la Vigilia Pascual, que de su ubicación nocturna hacía siglos que había sido desplazada a la mañana del Sábado Santo. La Constitución Sacrosanctum Concilium afirma que la liturgia es la cumbre de la actividad de la Iglesia, que tiende a la cima, y al mismo tiempo la fuente de donde mana toda su fuerza (n. 10). Se justifica esta fórmula, ya que

los trabajos apostólicos se ordenan a que, una vez hechos hijos de Dios por la fe y el bautismo, todos se congreguen en la unidad y en la Iglesia alaben a Dios, participen del Sacrificio y coman la cena del Señor (ib.).

No es la Iglesia una ONG para asegurar que la gente tenga tierra, techo y trabajo, -bien que su Doctrina Social apunte a la vigencia de una auténtica justicia en la sociedad-. Su finalidad esencial es que los hombres vivan en gracia de Dios y se encaminen al cielo. Lo digo con lenguaje sencillo, catequístico, 
no quiero negar que el compromiso por la justicia sea ocupación del cristiano; lo es, indudablemente. La celebración litúrgica es acción sagrada por excelencia, praecellenter (n. 7). Allí viene el problema: la liturgia es una realidad sagrada; el Concilio la llama continuamente sagrada liturgia (por ejemplo, desde el título del documento y a partir del enunciado de los principios generales). La sacralidad implica que la belleza y solemnidad de los ritos transmitan visible y audiblemente que se trata de acciones de Cristo, y no fabricaciones subjetivas del celebrante, el equipo de liturgia o el puñado de fieles a los que se identifica pomposamente como "la comunidad". La condición sacral se distingue por parámetros objetivos que están señalados en la composición eclesial de los mismos ritos. No puede introducirse en ese ámbito que comunica con la gloria celestial el ritmo de un show entretenido o el "fervor religioso" de un partido de fútbol. Aunque parezca mentira, no faltan los que -obispos incluidos- sostienen que ya no existe más diferencia entre lo sagrado y lo profano. Un hombre de la edad de piedra se escandalizaría de esa frívola apreciación. Cualquier tratado de fenomenología de la religión muestra que en todas las épocas, religiones y culturas existió "lo otro", lo "separado", diverso del mundo cotidiano, el ámbito propio de los dioses, al cual el hombre es invitado a introducirse. Sagrado va unido a sacramento, misterio, sacrificio. Cristo, por su misterio pascual, estableció la nueva, escatológica sacralidad y la introdujo en el corazón del mundo profano como anticipo transfigurante de la vida celestial. Como enseñó San León Magno: lo que fue visible en nuestro Redentor ha pasado a los ritos sacramentales. Lo que fue visible, esto es sus acciones teándricas, divino-humanas, y en cuanto humanas, propias de este mundo en el cual se hundió por su encarnación. En cierto modo, entonces, profanas. La deseducación de sacerdotes y fieles y devastación de la liturgia han sido el fruto amargo de la imposición del pretendido "espíritu del Concilio", una especie de "tiro por la culata" de las aspiraciones conciliares. Cito ad sensum una declaración de Pablo VI referida a la vida de toda la Iglesia, y que vale también para el desarrollo de la liturgia en los años 60 y 70 del siglo pasado, y después: Nosotros esperábamos una floreciente primavera, y sobrevino un crudo invierno. Esta expresión desencantada, a mi parecer, contrasta misteriosamente con el optimismo manifestado por Juan XXIII en el discurso de apertura del Concilio, cuando fustigó con dureza e ironía a los "profetas de calamidades". A pesar de todas las confusiones, la obra litúrgica del Vaticano II ha sido ilustrada por la extensión y actualización permanente que ofrecieron teólogos y liturgistas de nota, representada por último en el monumento que es el tomo XI de las Obras Completas de Joseph Ratzinger. Esa verdad, belleza y eficacia sobrenatural y humana de la divina liturgia tiene vigencia en 


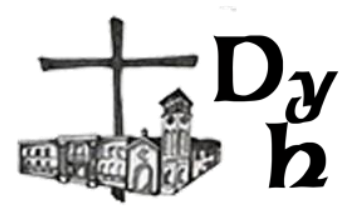

muchos lugares de la Iglesia, entre ellos nuestra arquidiócesis y este Seminario, que contó con la sabiduría y el trabajo de hombres como los monseñores Rau y Ruta, y que es y será continuada por las jóvenes generaciones.

El número 11 del Decreto Optatam -allí volvemos en nuestro discurso- concluye con esta admonición: todo el ordenamiento del Seminario, su ratio dice el texto, impregnado de amor y cultivo de la piedad, del silencio y de la solicitud por la ayuda fraterna, por la caridad, se entiende, ha de ser una cierta iniciación a la vida que luego deberá llevar el sacerdote. ¡Quiera Dios que lo logremos en nuestro Seminario! $Y$ que las amistades aquí forjadas $y$ cultivadas sirvan para que cuando los egresados y ordenados tengan que integrarse a un presbiterio que tiene su propia historia y por ello es forzosamente variopinto, no renuncien a los ideales que aquí han recibido y asumido y no se dejen unificar por la mediocridad.

El Decreto Presbyterorum ordinis sobre la vida y ministerio de los presbíteros fue trabajado $y$ discutido contemporáneamente al que he tratado de exponer en lo esencial. Estudiando en paralelo ambos textos se advierte la recíproca referencia y una común inspiración. Para permanecer en el ámbito del Vaticano II, señalo solamente dos o tres tópicos que han permanecido y han sido desarrollados luego por el magisterio sucesivo y por la interpretación teológica. El primero es el uso del vocabulario metafísico de la participación en las cinco fórmulas que expresan la naturaleza del presbiterado: participan del ministerio de Cristo, Maestro, Sacerdote y Rey, por el que la Iglesia es incesantemente edificada en la tierra; Cristo, por medio de los apóstoles hizo partícipes de su propia consagración y misión a los obispos, sucesores de aquéllos, y cuyo munus ministerii, en grado subordinado, es transmitido a los presbíteros; por su unión al Orden episcopal, ese oficio presbiteral participa de la autoridad con la que Cristo edifica, santifica y gobierna a su Cuerpo; ya que participan del ministerio de los apóstoles, reciben de Dios la gracia de desempeñar el sagrado ministerio del Evangelio. En este lugar se remite, en nota, a Romanos 15, 16, que en el original griego reza: ser liturgo de Cristo Jesús en favor de las naciones, desempeñando el sacerdocio del Evangelio. Quiere decir que la predicación evangélica extrae su fuerza del sacrificio del Gran Sacerdote, de modo que la congregatio societasque sanctorum sea ofrecida a Dios como un sacrificio universal. La expresión esta procede de "La Ciudad de Dios", de San Agustín (n. 2).

La impostación del ministerio y la vida de los presbíteros es teocéntrica y cristocéntrica, aunque tengan -tengamos, los obispos también- que ocuparnos de muchísimas cosas, incluso de carácter secular y que parecen, de suyo, más propias de los laicos. Pero 
no son los sacerdotes, no somos, dirigentes sociales sin más, y mucho menos agitadores ideologizados, como los que abundaron en los años 60 y 70 del siglo pasado, para ruina de la Iglesia y de la sociedad. Para que esta posición tan singular quede bien clara, el texto conciliar adopta una expresión compleja, pero comprensible y bella; se la podría calificar de dialéctica. Los presbíteros son en cierto modo segregados (segregantur), pero no para quedar separados (non tamen ut separentur) ni de los fieles ni del resto de la humanidad, sino para consagrarse totalmente (ut totaliter consecrentur) a la obra para la cual fueron asumidos por Dios en la gracia de la vocación. Así se describe la singular posición de los pastores de la Iglesia: estar cercanos a las necesidades de los hombres sin configurarse con el mundo. El pretexto de dejarse animar por el "espíritu del Concilio" pretensión que sobrevive aunque con otros argumentos en algunos ambientes- difundió en las décadas sucesivas una mundanización de la mentalidad, la vivencia y la acción de los sacerdotes, lo que a su vez determinó una reacción extremosa de signo contrario, aunque de extensión minoritaria, que menoscabó la plena humanidad con que corresponde presentarse a los hombres y la cercanía pastoral. Al final del capítulo primero, Presbyterorum Ordinis enumera: bondad de corazón -ique se note!-, sinceridad, fortaleza de ánimo y confianza, continuo afán de justicia, urbanidad. Un equilibrio de la personalidad que reclama, además de la rectitud doctrinal, una caridad ardiente alimentada en la intimidad con el Señor. Los sacerdotes diocesanos no somos monjes, aunque una dimensión monástica no puede faltar en el último rincón del alma. Nuestro género de vida es mixto: contemplación y apostolado. Contemplare et contemplata aliis tradere. Somos, como dice el Papa Francisco, pastores con olor a oveja. $\mathrm{Y}$ agrego yo: bien varones.

El capítulo segundo de Presbiterorum ordinis expone ampliamente los tria munera, el triple oficio de evangelizar, santificar y regir. En cuanto a la presentación del primero de ellos, leída a la distancia, llama la atención que no se diga nada sobre la fidelidad a la Gran Tradición de la Iglesia, a la verdad de la fe. Porque no es posible negar que siguió una devastación doctrinal dogmática y moral-, litúrgica y pastoral. El relativismo, la manipulación arbitraria del orden sacramental, la indigna secularización de la vida sacerdotal, la confusión populista entre piedad popular y superstición -valen lo mismo San Cayetano, San Expedito y el gauchito Gil - el desafuero instalado en las cátedras de los centros de formación y la incuria de quienes por oficio debían vigilar y corregir, explican el innegable retroceso de la Iglesia en la Argentina, como en otros países, según las diversas características de lugar y tiempo. Entre nosotros, cada año, miles de bautizados en la Iglesia Católica pasan a integrar los diversos grupos evangélicos. En estos se les 


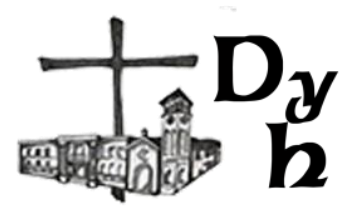

habla de Jesús y de la salvación, que es lo que primeramente esperan los pobres. La paciente obra de recuperación llevada a cabo por Pablo VI, Juan Pablo II y Benedicto XVI ha fortalecido y consolado a los fieles; ha sido un testimonio martirial de la perennidad y de la incorruptibilidad esencial de la katholikē. Es muy bella la presentación que el Decreto hace del ministerio de santificación que se ejerce mediante la celebración de los sacramentos, y sobre todo de la Eucaristía, en la que, como allí se dice, se contiene todo el bien espiritual de la Iglesia. Esta doctrina debió inspirar luego la reforma de los ritos y su aplicación concreta. ¿Cómo se llegó a la penosa generalización del descuido, la ruina del sentido de lo sagrado y la intromisión en ese ámbito de la arbitrariedad, la fealdad, las expresiones decadentes de gestos $y$ de música? Ocurrió y ocurre, a pesar de que el Concilio inculcaba: procuren los presbiteros cultivar debidamente la ciencia y el arte litúrgicos (n. 5). Subrayo: ciencia y arte. En cuanto al oficio de regir, gobernar, pastorear, se destaca que se trata de una potestad espiritual, un poder, que ha de ser ejercido eximia humanitate, es decir, con el amor paterno y fraterno que los hace verdaderos educadores en la fe, guías hacia la santidad (n. 6), y no patrones prepotentes.

La formación propiamente pastoral requiere la adquisición de instrumentos imprescindibles: el arte de hablar, no la mera locución sino también y sobre todo la homilética, la catequética, que en La Plata tiene una historia pionera y brillante; la praxis confessionis, ya que el ministerio de la reconciliación es fuente de sanación espiritual y a la vez psicológica; el conocimiento de los múltiples problemas sociales, como la desintegración de la familia, el abandono y la corrupción de los menores, la angustia cuando amenaza la miseria, la drogadicción, el maltrato y la discriminación de la mujer. No sólo es necesario saber algo acerca de estas cosas, sino llevar adelante los proyectos pastorales que intentan aliviar tales males. $Y$ todo por amor. No puedo olvidar la preparación para la pastoral educativa, el acompañamiento del impulso misionero de los laicos y el ejercicio de una sencilla y afectuosa paternidad para con los jóvenes. El sacerdote es ministro de la misericordia de Cristo. En realidad, además del cultivo de las disciplinas señaladas, y del inicio en la experiencia pastoral concreta, toda la vida del Seminario, incluyendo las minucias cotidianas, está ordenada a la formación de un corazón de pastor.

Los textos conciliares que he comentado, y que inspiraron las orientaciones prácticas adoptadas, serán siempre un punto de referencia insoslayable.

Observando las fotografías de los sacerdotes que pasaron por esta casa en generaciones sucesivas, se puede apreciar que el Seminario Mayor San José ha dado hombres 


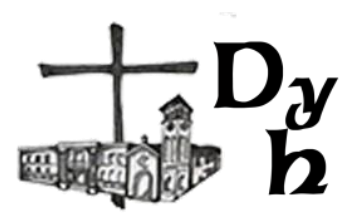

insignes a la Iglesia en nuestra patria, desde cardenales y obispos hasta párrocos que han sido durante décadas guías de su pueblo, más intelectuales de fuste, por los cuales la arquidiócesis puede sentirse legítima y humildemente orgullosa. Dentro de unos pocos años será la celebración del centenario, y la historia continuará después, hasta que Dios quiera, quizá, ¿cómo saberlo?, hasta que Cristo vuelva. Dixi. 